\title{
Metal-free one-pot synthesis of 2-substituted and 2,3-disubstituted morpholines from aziridines
}

\author{
Hongnan Sun, Binbin Huang, Run Lin, Chao Yang and Wujiong Xia*
}

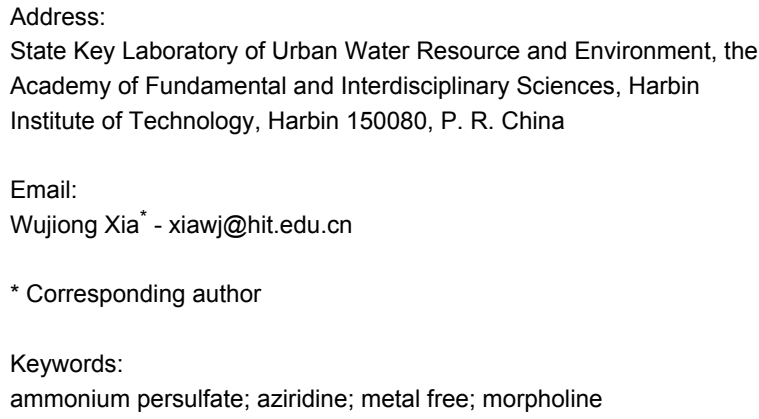

Beilstein J. Org. Chem. 2015, 11, 524-529. doi:10.3762/bjoc.11.59

Received: 21 February 2015

Accepted: 08 April 2015

Published: 22 April 2015

Associate Editor: C. Stephenson

(c) 2015 Sun et al; licensee Beilstein-Institut. License and terms: see end of document.

\begin{abstract}
The metal-free synthesis of 2-substituted and 2,3-disubstituted morpholines through a one-pot strategy is described. A simple and inexpensive ammonium persulfate salt enables the reaction of aziridines with halogenated alcohols to proceed via an $\mathrm{S}_{\mathrm{N}} 2$-type ring opening followed by cyclization of the resulting haloalkoxy amine.
\end{abstract}

\section{Introduction}

Morpholines are common structural cores of a broad range of biological and pharmacological natural or synthetically important organic molecules [1]. In particular, a number of 2-substituted and 2,3-disubstituted morpholines are clinically available drugs (Figure 1). For example, the trans-2,3-disubstituted morpholine, phendimetrazine (bontril), is a clinically available appetite suppressant [2], the 2-substituted morpholine, reboxetine, is a clinically active, efficacious, and well-tolerated antidepressant drug [3-5], and the cis-2,3-disubstituted morpholine, aprepitant, is approved for the use in the prevention of chemotherapy-induced nausea and vomiting [6].

In addition to pharmacological properties, morpholines are also used in organic synthesis as bases, catalysts, and chiral auxiliaries [7-13]. Thus, up to now, numerous strategies toward the synthesis of substituted morpholines have been reported [14-
23]. Despite these advances, the synthetic approach to 2 -substituted and 2,3-disubstituted morpholines is still scarce. Recently, Ghorai and co-workers disclosed an intriguing strategy for the synthesis of substituted morpholines through $\mathrm{Cu}(\mathrm{OTf})_{2}-$ catalyzed ring-opening/closing reactions of aziridines and halogenated alcohols in high yield and enantioselectivity (Scheme 1a) [21]. However, this method suffered from the need for transition metal catalysts and low temperatures in the initial stage. Thus, the discovery of an operationally simple and ecofriendly synthetic approach is a desirable complement to current methodologies.

Recently we have reported the visible light-mediated ring opening of aziridines by a number of nucleophiles, such as $\mathrm{LiBr}, \mathrm{NaN}_{3}$ and alcohols [24]. As a part of an ongoing program on the ring opening of aziridines [25-31], we have developed an 


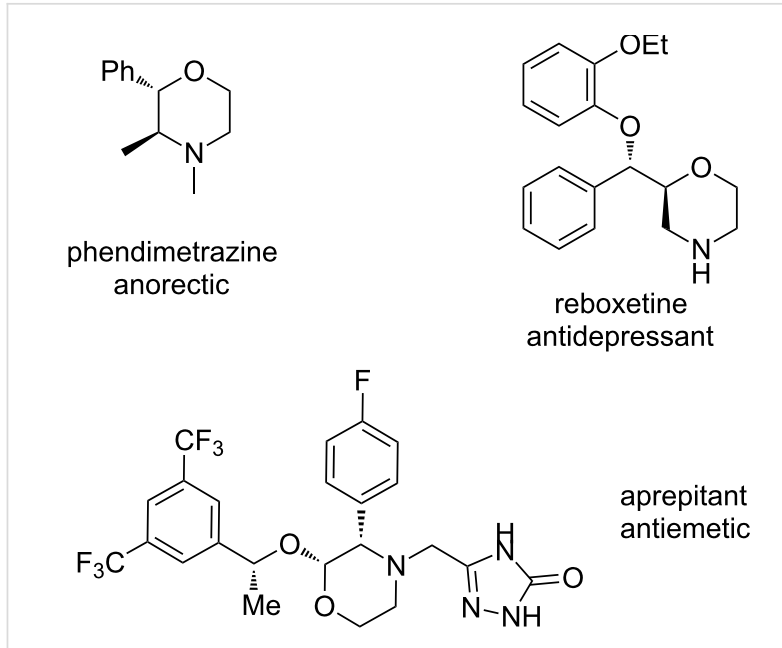

Figure 1: Pharmaceutically active 2- and 2,3-disubstituted morpholines.

efficient method for the synthesis of 2-substituted and 2,3disubstituted morpholines from aziridines utilizing a simple and inexpensive ammonium persulfate salt as the oxidant at room temperature (Scheme 1b) [32,33].

\section{Results and Discussion}

Our investigation started with the treatment of 2-phenyl- $N$ tosylaziridine (1a) with 2-chloroethanol in the presence of sodium persulfate at room temperature for $13 \mathrm{~h}$ (Table 1). To our delight, NMR studies showed that chloroethoxyamine 2a is observed as the only ring-opening product. After screening different persulfates, in concordance with Zeng [32], we found that ammonium persulfate $\left(\left(\mathrm{NH}_{4}\right)_{2} \mathrm{~S}_{2} \mathrm{O}_{8}\right)$ is superior to $\mathrm{Na}_{2} \mathrm{~S}_{2} \mathrm{O}_{8}$ and $\mathrm{K}_{2} \mathrm{~S}_{2} \mathrm{O}_{8}$ in the transformation, leading to chloroethoxyamine $2 \mathbf{a}$ in an excellent yield (93\%) in short time.

Table 1: Metal-free ring opening of 2-phenyl- $N$-tosylaziridine (1a) with 2-chloroethanol using different persulfates as oxidant. ${ }^{a}$

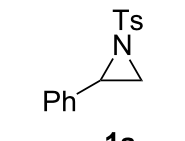

$1 \mathbf{a}$

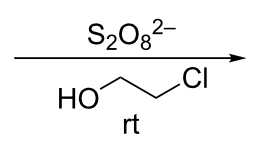<smiles>[PH3-][Mg]CC(OCCCl)c1ccccc1</smiles>

\begin{tabular}{llll}
\hline Entry & $\mathrm{S}_{2} \mathrm{O}_{8}{ }^{2-}$ & Time $(\mathrm{h})$ & Yield $(\%)^{\mathrm{b}}$ \\
\hline 1 & $\mathrm{Na}_{2} \mathrm{~S}_{2} \mathrm{O}_{8}$ & 13 & 94 \\
2 & $\mathrm{~K}_{2} \mathrm{~S}_{2} \mathrm{O}_{8}$ & 16 & 96 \\
3 & $\left(\mathrm{NH}_{4}\right)_{2} \mathrm{~S}_{2} \mathrm{O}_{8}$ & 0.5 & 93
\end{tabular}

aAziridine $1 \mathrm{a}(0.3 \mathrm{mmol}),\left(\mathrm{NH}_{4}\right)_{2} \mathrm{~S}_{2} \mathrm{O}_{8}(0.6 \mathrm{mmol}, 2$ equiv) in 2-chloroethanol (10 equiv) as the solvent; ${ }^{\text {isolated yield. }}$

Encouraged by the result that treatment of 2a with $\mathrm{KOH}$ at room temperature in THF led to morpholine $\mathbf{3 a}$ in $90 \%$ yield, we performed the reaction by addition of $\mathrm{KOH}$ to the mixture of 1a and $\left(\mathrm{NH}_{4}\right)_{2} \mathrm{~S}_{2} \mathrm{O}_{8}$ in 2-chloroethanol after the reaction and hoped to prepare 3a in one pot. Gratifyingly the reaction proceeded smoothly to furnish $\mathbf{3 a}$ in $93 \%$ yield (Scheme 2).

(a) previous work

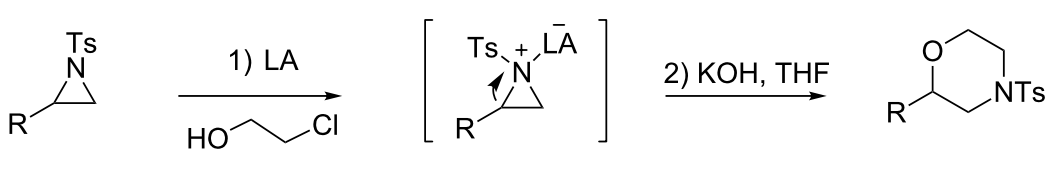

(b) this work

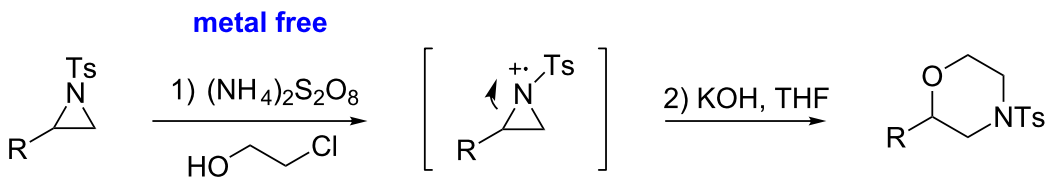

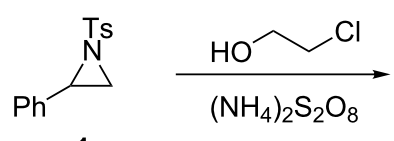

$1 \mathbf{a}$

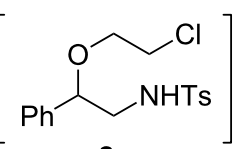

$2 \mathbf{a}$

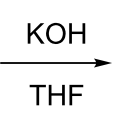

THF<smiles></smiles>

$3 a$ 
To investigate the scope of this methodology, various substituted aziridines were prepared from the corresponding alkenes and submitted them to the reaction conditions. As shown in Table 2, both electron-deficient and electron-rich 2-aryl-substi- tuted aziridines $\mathbf{1} \mathbf{a}-\mathbf{j}$ were well tolerated and the desired morpholines $\mathbf{3 a}-\mathbf{j}$ were obtained in good yields (Table 2, entries 1-10). $N$-Tosylaziridine $1 \mathbf{k}$ was also a viable substrate for the reaction leading to the corresponding bicyclic morpholine $\mathbf{3 k}$ in

Table 2: Metal-free one-pot synthesis of morpholines from aziridines. ${ }^{\text {a }}$<smiles>[R]C1[N]C1[R]</smiles>

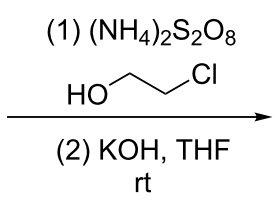

$\mathrm{rt}$<smiles>[R]C1=[N+](C)CCOC1[R]</smiles>

3<smiles>[R]C1OCCN2CCCCCCCC12[R]</smiles>

4

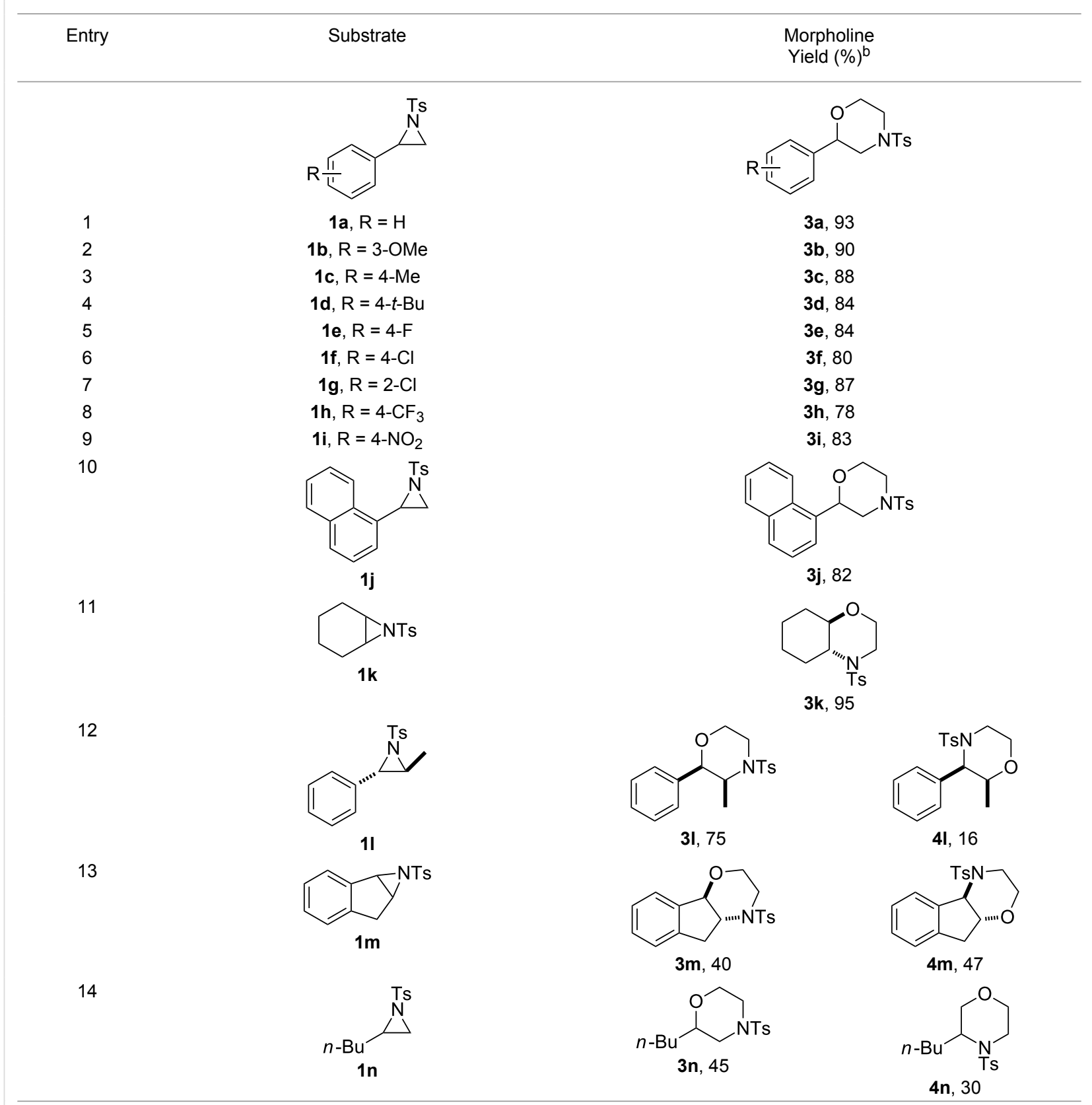

aln all cases 2-chloroethanol served as the solvent; ${ }^{\text {isolated yield. }}$ 
95\% yield (Table 2, entry 11 ). In addition, the reaction of 2,3disubstituted aziridines (acyclic and/or cyclic ones), separable mixtures of regioisomers $\mathbf{3 1}, \mathbf{m}$ and $\mathbf{4 1}, \mathbf{m}$ were obtained arising from isomeric ring opening (Table 2, entries 12 and 13). We speculated that the observed regioselectivity might depend on the combined action of electronic effects and the position of substitution [31]. Under identical reaction conditions, the separable 2-butylmorpholine $3 n$ and 3-butylmorpholine $4 n$ could be easily prepared from aziridine $\mathbf{1 n}$ (Table 2 , entry 14).

To further investigate the applicability of this strategy in organic synthesis, we next performed a series of experiments to determine the potential of the straightforward synthesis of optically pure morpholines from chiral aziridines. The initial investigation was carried out by the replacement of racemic 2-phenyl- $N$-tosylaziridine (1a) with optically pure $(S)$-2-phenyl1 -tosylaziridine under the standard reaction conditions. To our delight, $(R)$-3a was obtained in $93 \%$ yield and $70 \%$ ee (Scheme 3 ). For optically pure $(S)$-2-alkyl-substituted aziridines 1p,q, separable $(R)$-2-alkylmorpholines 3p,q and (S)-3-alkylmorpholines $4 \mathbf{p}, \mathbf{q}$ were prepared in pure forms (95-99\% ee) and low to moderate overall yields. Furthermore, the enantiospecific synthesis of seven and eight-membered homologues of morpholine was also conducted to extend the potential application of the strategy. For example, when 2-chloroethanol was replaced by 3-bromopropanol, the seven-membered product $(R)$-3ab was obtained in $72 \%$ yield and $84 \%$ ee. Similarly, reaction of (R)-2-phenyl- $N$-tosylazetidine (10) with 2-bromoethanol and/or 3-bromopropanol under the one-pot reaction conditions, afforded the seven-membered product $(S)$-3o and the eight- membered compound $(S)$-3ob in $65 \%$ and $60 \%$ yield with $52 \%$ and $67 \%$ ee, respectively.

Based on the above results, a viable mechanism was proposed as shown in Scheme 4. Initially, aziridine 1a might participate in single-electron transfer (SET) with the persulfate anion to render the radical cation $\mathbf{A}[32,34]$. Concerted ring opening and nucleophilic addition leads to amino radical intermediate $\mathbf{B}$, which is converted to the haloalkoxy amine intermediate $\mathbf{2 a}$ after abstraction of one hydrogen atom from alcohol. Finally, an intramolecular ring closure affords the morpholine product $\mathbf{3 a}$ in the presence of $\mathrm{KOH}$ [21].

\section{Conclusion}

In conclusion, we have developed a simple and practicable metal-free protocol for the synthesis of 2-substituted and 2,3disubstituted morpholines. Compared with the previous procedure, this reaction is conducted with a simple and inexpensive ammonium persulfate salt as the oxidant to realize the ring opening of aziridines for the reaction with haloalcohols through a radical cation intermediate pathway. Furthermore, a range of optically pure morpholines could be achieved by the use of chiral aziridines.

\section{Experimental}

General procedure for the one-pot synthesis of morpholines: A $10 \mathrm{~mL}$ round bottom flask equipped with a magnetic stirring bar was charged with aziridine/azetidine 1 ( $0.3 \mathrm{mmol}, 1$ equiv), $\left(\mathrm{NH}_{4}\right)_{2} \mathrm{~S}_{2} \mathrm{O}_{8}$ (137 mg, $0.6 \mathrm{mmol}, 2$ equiv) and haloalcohol (10 equiv). The mixture was stirred at $\mathrm{rt}$ for the appropriate time Scheme 3: Metal-free one-pot synthesis of optically pure morpholine derivatives from chiral aziridines. 


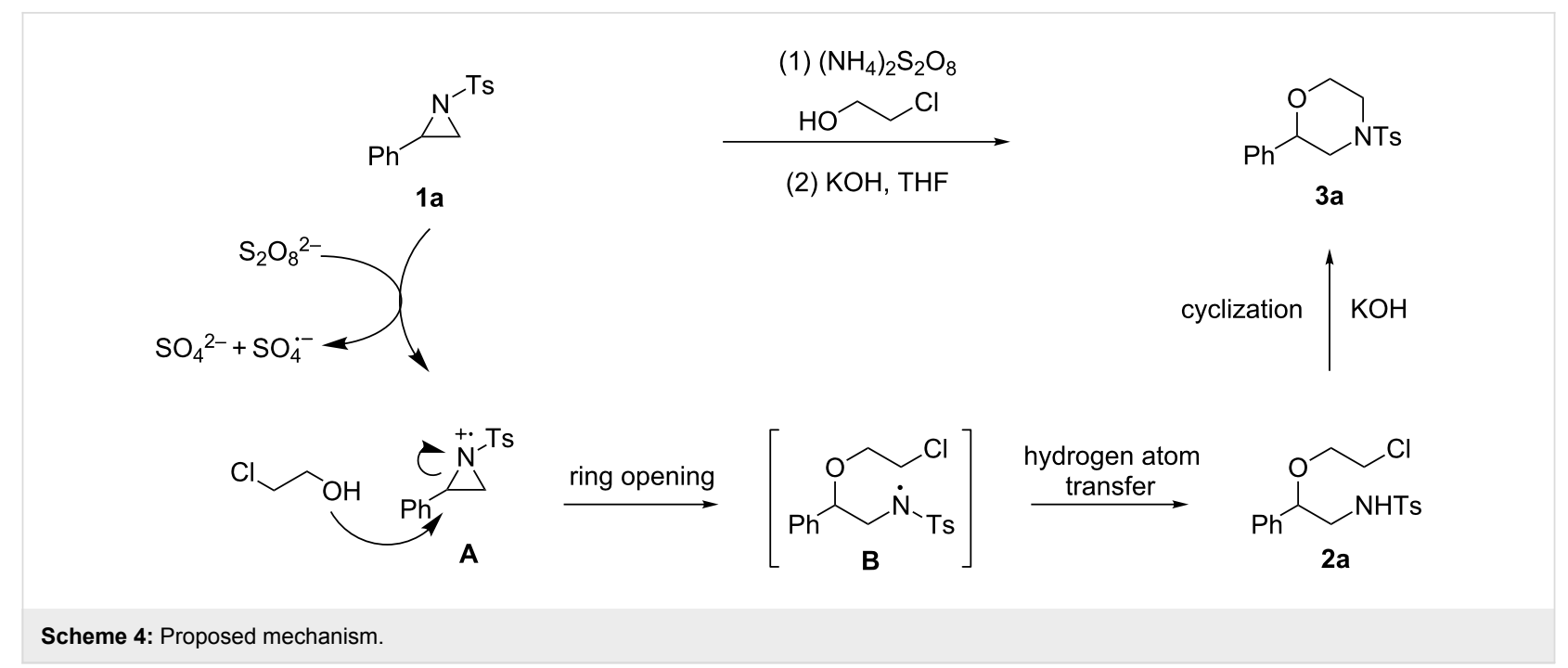

until the starting material disappeared completely (monitored by TLC). Then, $5.0 \mathrm{~mL}$ THF and excess $\mathrm{KOH}$ (12 equiv) were added to the reaction mixture and the mixture was stirred at $\mathrm{rt}$. After the reaction was completed, the resulting suspension was quenched with saturated aqueous sodium bicarbonate solution and extracted with ethyl acetate. The organic layers were combined, washed with brine and dried over anhydrous sodium sulfate. Solvents were removed under reduced pressure and the residue was purified by column chromatography on silica gel using ethyl acetate/hexane mixtures to afford the pure products.

\section{Supporting Information}

\section{Supporting Information File 1}

Experimental procedures, characterization data and copies of ${ }^{1} \mathrm{H}$ and ${ }^{13} \mathrm{C}$ NMR spectra for products.

[http://www.beilstein-journals.org/bjoc/content/ supplementary/1860-5397-11-59-S1.pdf]

\section{Acknowledgements}

We are grateful for the financial supports from China NSFC (Nos. 21002018, 21072038 and 21472030), SKLUWRE (No. 2015DX01), the Fundamental Research Funds for the Central Universities (Grant No. HIT.BRETIV.201310) and HLJNSF (B201406).

\section{References}

1. Wijtmans, R.; Vink, M. K. S.; Schoemaker, H. E.; van Delft, F. L.; Blaauw, R. H.; Rutjes, F. P. J. T. Synthesis 2004, 641-662. doi:10.1055/s-2004-816003

2. Rothman, R. B.; Baumann, M. H. Curr. Top. Med. Chem. 2006, 6, 1845-1859. doi:10.2174/156802606778249766
3. Hajós, M.; Fleishaker, J. C.; Filipiak-Reisner, J. K.; Brown, M. T.; Wong, E. H. F. CNS Drug Rev. 2004, 10, 23-44. doi:10.1111/j.1527-3458.2004.tb00002.x

4. Wong, E. H. F.; Sonders, M. S.; Amara, S. G.; Tinholt, P. M.; Piercey, M. F. P.; Hoffmann, W. P.; Hyslop, D. K.; Franklin, S.; Porsolt, R. D.; Bonsignori, A.; Carfagna, N.; McArthur, R. A. Biol. Psychiatry 2000, 47, 818-829. doi:10.1016/S0006-3223(99)00291-7

5. Scates, A. C.; Doraiswamy, P. M. Ann. Pharmacother. 2000, 34, 1302-1312. doi:10.1345/aph.19335

6. Pendergrass, K.; Hargreaves, R.; Petty, K. J.; Carides, A. D.; Evans, J. K.; Horgan, K. J. Drugs Today 2004, 40, 853-863. doi:10.1358/dot.2004.40.10.863745

7. Takahata, H.; Takahashi, S.; Kouno, S.-i.; Momose, T. J. Org. Chem. 1998, 63, 2224-2231. doi:10.1021/jo971995f

8. Betancort, J. M.; Barbas, C. F., III. Org. Lett. 2001, 3, 3737-3740. doi:10.1021/ol0167006

9. Dave, R.; Sasaki, N. A. Org. Lett. 2004, 6, 15-18. doi:10.1021/ol035998s

10. Mayer, S.; List, B. Angew. Chem., Int. Ed. 2006, 45, 4193-4195. doi:10.1002/anie.200600512

11. Quin, Y.-C.; Pu, L. Angew. Chem., Int. Ed. 2006, 45, 273-277. doi:10.1002/anie.200503206

12. Nelson, S. G.; Wang, K. J. Am. Chem. Soc. 2006, 128, 4232-4233. doi:10.1021/ja058172p

13. Mossé, S.; Laars, M.; Kriis, K.; Kanger, T.; Alexakis, A. Org. Lett. 2006, 8, 2559-2562. doi:10.1021/ol0607490

14. Leonard, N. J.; Jann, K. J. Am. Chem. Soc. 1960, 82, 6418-6419. doi:10.1021/ja01509a061

15. Lenoard, N. J.; Jann, K. J. Am. Chem. Soc. 1962, 84, 4806-4813. doi:10.1021/ja00883a035

16. Kogami, Y.; Okawa, K. Bull. Chem. Soc. Jpn. 1987, 60, 2963-2965. doi:10.1246/bcsj.60.2963

17. Pedrosa, R.; Andrés, C.; Mendiguchia, P.; Nieto, J. J. Org. Chem. 2006, 71, 8854-8863. doi:10.1021/jo061547k

18. Sladojevich, F.; Trabocchi, A.; Guarna, A. J. Org. Chem. 2007, 72, 4254-4257. doi:10.1021/jo070036a

19. Metro, T.-X.; Pardo, D. G.; Cossy, J. J. Org. Chem. 2008, 73, 707-710. doi:10.1021/jo701554h 
20. Yar, M.; McGarrigle, E. M.; Aggarwal, V. K. Angew. Chem., Int. Ed. 2008, 47, 3784-3786. doi:10.1002/anie.200800373

21. Ghorai, M. K.; Shukla, D.; Das, K. J. Org. Chem. 2009, 74, 7013-7022. doi:10.1021/jo901297d

22. Wang, L.; Liu, Q.-B.; Wang, D.-S.; Li, X.; Han, X.-W.; Xiao, W.-J.; Zhou, Y.-G. Org. Lett. 2009, 11, 1119-1122. doi:10.1021/ol802862p

23. Sawant, R. T.; Stevenson, J.; Odell, L. R.; Arvidsson, P. I. Tetrahedron: Asymmetry 2013, 24, 134-141. doi:10.1016/j.tetasy.2012.12.004

24. Sun, H.; Yang, C.; Lin, R.; Xia, W. Adv. Synth. Catal. 2014, 356, 2775-2780. doi:10.1002/adsc.201400476

25. Hu, X. E. Tetrahedron 2004, 60, 2701-2743. doi:10.1016/j.tet.2004.01.042

26. Fokin, V. V.; Wu, P. Epoxides and Aziridines in Click Chemisty. In Aziridines and Epoxides in Organic Synthesis; Yudin, A. K., Ed.; Wiley-VCH: Weinheim, 2006; pp 443-475. doi:10.1002/3527607862.ch12

27. Watson, I. D. G.; Yu, L.; Yudin, A. K. Acc. Chem. Res. 2006, 39, 194-206. doi:10.1021/ar050038m

28. Singh, G. S.; D'hooghe, M.; De Kimpe, N. Chem. Rev. 2007, 107, 2080-2135. doi:10.1021/cr0680033

29. Schneider, C. Angew. Chem., Int. Ed. 2009, 48, 2082-2084. doi:10.1002/anie.200805542

30. Lu, P. Tetrahedron 2010, 66, 2549-2560. doi:10.1016/j.tet.2010.01.077

31. Stanković, S.; D'hooghe, M.; Catak, S.; Eum, H.; Waroquier, M.; Van Speybroeck, V.; De Kimpe, N.; Ha, H.-J. Chem. Soc. Rev. 2012, 41, 643-665. doi:10.1039/C1CS15140A

32. Wei, Y.; Tang, J.; Cong, X.; Zeng, X. Green Chem. 2013, 15, 3165-3169. doi:10.1039/C3GC41403E

33. Xia, W. J.; Sun, H. N.; Yang, C. A method of synthesizing compounds Morpholinium. Chin. Pat. Appl. CN104193695 A, Dec 10, 2014.

34. Gaebert, C.; Mattay, J.; Toubartz, M.; Steenken, S.; Müller, B.; Bally, T. Chem. - Eur. J. 2005, 11, 1294-1304. doi:10.1002/chem.200400557

\section{License and Terms}

This is an Open Access article under the terms of the Creative Commons Attribution License (http://creativecommons.org/licenses/by/2.0), which permits unrestricted use, distribution, and reproduction in any medium, provided the original work is properly cited.

The license is subject to the Beilstein Journal of Organic Chemistry terms and conditions:

(http://www.beilstein-journals.org/bjoc)

The definitive version of this article is the electronic one which can be found at: $\underline{\text { doi:10.3762/bjoc. } 11.59}$ 